\title{
Allocation in LCA of Wood-based Products Experiences of Cost Action E9
}

\author{
Part I. Methodology \\ Gerfried Jungmeier $^{1 *}$, Frank Werner ${ }^{2}$, Anna Jarnehammar ${ }^{3}$, Catharina Hohenthal ${ }^{4}$ and Klaus Richter ${ }^{2}$ \\ 1 JOANNEUM RESEARCH, Institute of Energy Research, Elisabethstrasse 5, A-8010 Graz, Austria \\ ${ }^{2}$ Federal Laboratories for Materials Testing and Research (EMPA), Duebendorf, Switzerland \\ ${ }^{3}$ Trätek, Swedish Institute for Wood Technology Research, Stockholm, Sweden \\ ${ }^{4} \mathrm{KCL}$, Helsinki, Finland
}

$\overline{\text { * Corresponding author (gerfried.jungmeier@joanneum.at) }}$

Preamble. The treatment of allocation is a crucial matter in the LCA of wood-based products, because the allocation method might influence the results significantly. This paper outlines in two parts - Methodology (Part I) and Examples (Part II) - practical experiences for the treatment of allocations for LCAs of wood-based products that are the result of the Cost Action E 9 'Life cycle assessment of forestry and forest products' and reflect the experience of Cost E9 delegates. Part II will be published in Int J LCA 7 (6) 2002.

\section{DOI: http://dx.doi.org/10.1065//ca2002.08.091.1}

\section{Abstract}

Goal and Background. The treatment of allocation in the descriptive LCA of wood-based products has been discussed for a long time and different solutions have been presented. In general, it is accepted that the influence of different allocation procedures on the results of LCA of wood-based products can be very significant. This paper is a result of the Cost Action E9 'Life cycle assessment of forestry and forest products' and represents the experience of involved Cost $\mathrm{E} 9$ delegates.

Objective. Wood is a renewable material that can be used for wood products and energy production. Consistent methodological procedures are needed in order to correctly address the twofold nature of wood as a material and fuel, the multi-functional wood processing generating large quantities of co-products, and reuse or recycling of paper and wood. Ten different processes in LCAs of wood-based products are identified, where allocation questions can occur: forestry, sawmill, wood industry, pulp and paper industry, particle board industry, recycling of paper, recycling of wood-based boards, recycling of waste wood, combined heat and power production, landfill.

Methodology. Following ISO 14041 a step-wise procedure for system boundary setting and allocation are outlined. As a first priority allocation should be avoided by system expansion, thus adding additional functions to the functional unit. Alternatively, the avoided-burden approach can be followed by subtracting substituted functions of wood that are additionally provided. If allocation cannot be avoided, some allocations methods from case studies are described.

Conclusions. The following conclusions for allocation in LCA of wood-based products are given. 1) Avoid allocation by expansion of system boundaries by combining material and energy aspects of wood, meaning a combination of LCA of wood products and of energy from wood with a functional unit for products and energy. 2) Substitute energy from wood with conventional energy in the LCA of wood products to get the func- tional unit of the wood product only, but identify the criteria for the substituted energy. 3) Substitution of wooden products with non-wooden products in LCA of bioenergy is not advisable, because the substitution criteria can be too complex. 4) If avoiding allocation is not possible, the reasons should be documented. 5) Different allocation procedures must be analysed and documented. In many cases, it seems necessary to make a sensitivity analysis of different allocation options for different environmental effects. It can also be useful to get the acceptance of the chosen allocation procedure by external experts. 6) Different allocation factors, e.g. mass or economic value, are allowed within the same LCA. 7) For allocation of forestry processes it is necessary to describe the main function of the forest where the raw material is taken out. In some cases different types or functions of forests must be considered and described. 8) Regarding the experiences from the examples, the following most practical allocation for some specific processes are identified: forestry: mass or volume; sawmill: mass or volume and proceeds; wood industry: mass and proceeds.

Keywords: Allocation; bioenergy; forest products; forestry; Cost E9; life cycle assessment; wood products

\section{Introduction}

The treatment of allocation in the descriptive LCA of woodbased products has been discussed for long time and different solutions have been presented. It is accepted that the influence of different allocation procedures on the results of LCA of wood-based products can be very significant. That is why the chosen allocation procedures must be described and justified in detail, but they still remain a point for controversial discussion in each case study. This paper outlines practical experiences for the treatment of allocations for LCAs of wood-based products that are the result of the Cost Action $\mathrm{E} 9$ 'Life cycle assessment of forestry and forest products' and reflect the experience of Cost E9 delegates. 
First, the inherent linkage of wood products and energy from biomass ('bioenergy') is shown. After some methodological remarks on allocation options, an approach for solving the allocation problems related to wood and its products is discussed based on the limited number of relevant processes. From that, a list of preferences for different allocation situations is derived, which are illustrated in some case studies. Finally, the experiences are summarised for LCA practitioners in the field of LCA of forestry, wood, bioenergy and wooden products.

\section{Problem Description}

One of the basic characteristics of wood is its twofold nature as a widely used material and an energy carrier. Due to this fact different LCAs have been made concentrating on one of the two aspects, namely LCA on:

- wood-based products (e.g. particle boards, timber, paper) and on

- bioenergy (e.g. wood chips for heat supply).

A closer look at the two groups of LCAs of wood-based products shows that an LCA of wood products usually consists of three main phases (Fig. 1):

1. production (e.g. fibre wood to pulp and paper production and printing of a newspaper)

2. use (e.g. reading the newspaper) and

3. end of life (e.g. combustion of newspaper)

In LCA of wood-based products, the infrastructure of the production facilities is usually not taken into account. It is assumed that the infrastructure for the production of different wood products or for products from other materials with the same functions are similar, and that the differences are negligible compared to the over-all environmental impacts of the product's life cycle (see e.g. Werner et al. [1]). The infrastructure can have more significant influence when comparing energy systems (see e.g. Frischknecht et al [2]).

An LCA on bioenergy is normally structured according to the following three phases (see Fig. 1):

1. construction (e.g. building the facilities of a power plant)

2. operation (e.g. supply of biomass fuel and energy generation) and

3. dismantling (e.g. decommissioning of the facilities)

Within both types of LCA the twofold nature of wood is a key aspect which has to be dealt with in an adequate manner. Fig. 1 shows the linkage between the material and energetic use of biomass:

- forestry provides biomass for both the production phase of wood products and for the operation phase of the bioenergy generation

- production and end of life phases of wood products can provide biomass for the operation phase of the bioenergy generation

- operation phase of bioenergy generation can provide energy for the production phase of wood products (e.g. wood drying).

The close linkage between the material use and the use for energy production of wood causes one of the main allocation problems for LCAs of wood and its products.

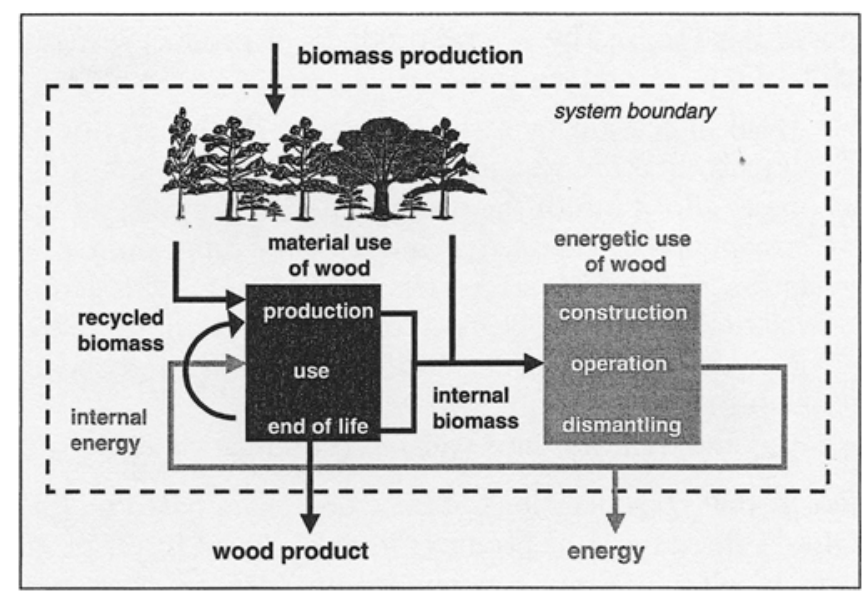

Fig. 1: Linkage between the material and energetic use of wood in the LCA of wood-based products

Another characteristic of the wood chain is the generation of high amounts of co-products during the different production steps. This is especially true for products of solid wood where the material yield for a solid wood product lies at around or even less than $50 \%$ of the sawn log. Thus, the generation of various co-products in a production process results in another typical and crucial allocation problem for the wood chain.

\section{Methodological Considerations}

First, general options for dealing with allocation problems are shown and processes, which might need allocation in LCA of wood-based products, are discussed. Afterwards, two procedures - first and second priority - to avoid allocation are described and different allocation procedures are outlined.

\subsection{Allocation overview}

According to ISO 14040 , allocation is defined as partitioning the input or output flows of a unit process to the product system under study. Allocation means that the environmental aspects are partitioned among the different products and/or among subsequent product systems. Three generic processes for allocation are distinguished:

- multi-output processes providing e.g. sawn timber, sidecuts and sawdust from the sawmill, where the material flows of the process and its up-stream processes have to be allocated to the various outputs,

- multi-input processes, e.g. the combustion of different fractions of waste wood, where the emissions and the generated energy have to be allocated to the different products or product systems,

- recycling and reuse, where, besides the recycling process itself, primary production and final disposal may have to be allocated to several subsequent product systems.

As a guiding principle, allocation procedures should (...) approximate as much as possible (...) fundamental inputoutput relationships and characteristics (ISO 14 041). As a procedure for modelling situations where a process could 
possibly be shared by several products or product systems, ISO 14041 recommends to

- avoid allocation by a subdivision of the process or an extension of the system boundary

- make allocation of the process and of its preceding upstream processes based on fundamental input-output relationship and characteristics (ISO 14 041). This causal relationship should be based on physical relationship (reflecting the physical, chemical or biological interdependence of processes and their products)

- use other relationships (such as economic value)

For further considerations of the wood chain based on ISO 14041 three types of products in the LCA of forest products, wood, bioenergy and wooden products are characterised according to their relative market price:

- co-products with a high market price,

- co-products with a low market price and

- waste with a 'negative' market value.

\subsection{Allocations in LCA of wood-based products}

A close look at all possible processes in LCA of wood-based products shows that at least 10 processes in the wood chain are subject to allocation (Fig. 2). These 10 processes can be subdivided in multi-output processes (e.g. forestry, sawmill), multi-input processes (e.g. energy generation in CHP plant) that are typical end-of-life situations and processes related to reuse and recycling, which may imply that the inputs and outputs associated with unit processes for extraction and processing of raw materials and final disposal of products are to be shared by more than one product system (ISO 14 041). The recycling issue has to be considered under different aspects of multi-functionality:

a) the recycling process itself as a bi-functional process serving as a waste treatment process as well as for secondary material extraction, and

b) the aspect of open/closed loop recycling which may require allocating primary production and final disposal as shared processes to several subsequent product systems.

Much methodological effort has already been made to properly address the recycling of paper (e.g. Ekvall [3], Plätzer et al. [4], Reichart et al. [5]; ISO 14 049). For wooden products, the recycling issue has commonly been solved by the cut-off procedure (see e.g. Consoli et al. [6]) - thus mainly by system boundary setting.

Remark: The so-called 'other functions' of forestry, like recreation and bio-diversity, are not further treated in this paper (see Part II, section 1.1).

Fig. 2 illustrates the whole wood chain with its different interlinkages of material and energy flows. Forestry provides the raw material for a variety of different products, such as particle boards, paper, wood products, heat and/or electricity for consumption. For the functional unit of LCA of woodbased products this means that allocation can be avoided by a system expansion taking all these different products into account. With this whole-system approach all the woodrelated material flows are internalised while the system provides various products. As a consequence of the system expansion, a variety of functions is added up to the 'functional unit', as is shown in the following example:

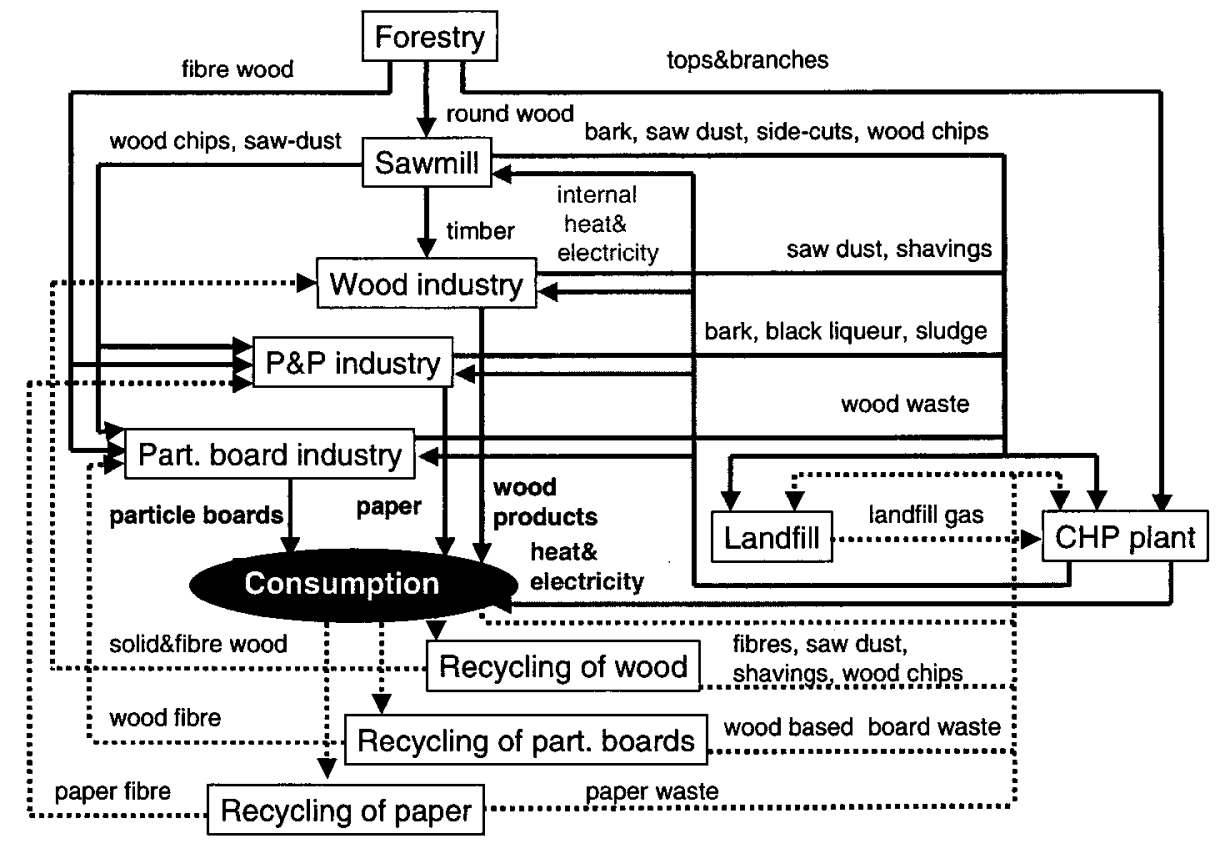

Fig. 2: Processes in the LCA of wood-based products that might require allocation (simplified, transportation, and other upstream environmental aspects of processes are not shown) 
$\mathrm{CH}_{4}$ emission is $6 \mathrm{t}$ for the consumption of 1 wooden table, $0.5 \mathrm{t}$ of paper, $13 \mathrm{~m}^{3}$ particle boards, $1 \mathrm{GWh}$ electricity and 2 GWh heat.

Of course, this 'functional unit' is not very manageable, especially in comparative studies. Also, the data requirements of this approach are high. Depending on the goal and scope of the study, this extensive functional unit can be reduced by allocation concentrating on one type of material use and energy from the wood combustion. This leads, e.g. to the following functionals:

- LCA particle boards: $1 \mathrm{~m}^{3}$ particle board + y $\mathrm{kWh}$ electricity $+\mathrm{z} k$ Wh heat

- LCA paper products: $1 \mathrm{t}$ paper (if all energy is used as internal energy) or $1 \mathrm{t}$ paper $+\mathrm{y} \mathrm{kWh}$ electricity $+\mathrm{z} \mathrm{kWh}$ heat (if not all energy is used as internal energy)

- LCA wooden products: 1 wooden product + y $\mathrm{kWh}$ electricity $+\mathrm{z} \mathrm{kWh}$ heat (if co-products are only used for energy)

- LCA bioenergy for heat and electricity: y kWh electricity $+\mathrm{z} \mathrm{kWh}$ heat

- LCA sawmill: $1 \mathrm{~m}^{3}$ timber $+\mathrm{y} \mathrm{kWh}$ electricity $+\mathrm{z} \mathrm{kWh}$ heat (if co-products from sawmill are only used for energy)

As system expansion and substitution are first priority strategies for dealing with multifunctional situations, their application in specific LCAs of wood-based products are presented in the following section.

Remark. For the allocation issues it has to be considered that the carbon content and the embodied energy content are material-inherent properties of wood. C-uptake and Crelease of wood as well as its embodied energy content are intrinsically related to the mass of wood. Allocating the $\mathrm{CO}_{2}$ uptake to just one of several co-products generates artefacts that do not consider the causal, biological relationships of wood (see e.g. De Feyter [7]). A 'warning' example is given in Part II, section 1.3 in the case study on window frames.

\subsection{First priority procedures:}

Avoiding allocation by system expansion or substitution

\subsubsection{System expansion}

The comparison of wooden products to non-wooden products must be based on equal functional units. An example is given in (Fig. 3) illustrating system expansion to avoid allocation): Two tables made of wood and aluminium are compared on the basis of the functional unit 'per table'. During the production of the wooden table, co-products originate, which - used for energy generation - can substitute other energy generating systems (e.g. systems based on fossil fuels). The allocation problem can be avoided if the system boundary is extended to include energy production. This is associated with a change of the functional unit 'per table' into 'per table and $\mathrm{x} \mathrm{kWh}$ of heat'. Now, the LCA of a wooden table and $\mathrm{x} \mathrm{kWh}$ of bioenergy can be compared to an aluminium table and $\mathrm{x} \mathrm{kWh}$ of fossil energy (see Jungmeier et al. [8]. This is the ideal situation referring to the linkage of material and energetic use of biomass.

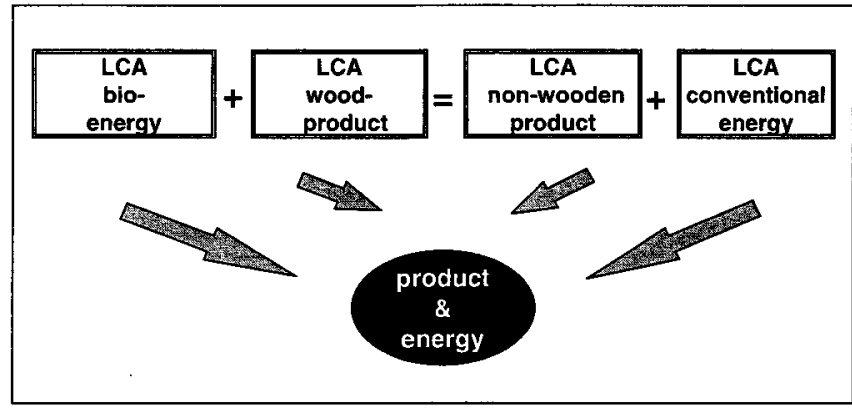

Fig. 3: Comparison of wood-based products with non-wooden products in an LCA by system expansion

\subsubsection{Substitution}

Substitution can be seen as a special case of system expansion, but substitution follows another reasoning: On the right side in Fig. 3 the supply of a non-wooden product and of fossil energy can be considered independently. This means that, in the LCA of a wooden product, the energy generated substitutes other energy carriers (e.g. fossil fuels). Therefore, the equivalent process of the fossil energy supply can be given as credit to the wooden product as avoided environmental effects. The equivalent process is the supply of fossil energy that is substituted by bioenergy. In this case, the functional unit is only the wooden product (Fig. 4). For the substitution of conventional energy, however, certain criteria have to be taken into account (see Jungmeier et al. [8]), which can lead to a substitution rate of less than $100 \%$. Examples for these substitution criteria are kind of energy, energy supply/demand characteristic, kind of substituted energy and costs.

In LCA of bioenergy, a substitution of the wood product is not advisable or possible. Substitution of wooden products in LCA of energy does not seem to be practicable, because substitution criteria for wooden products and non-wooden products are very complex to define. As an example, in an LCA of bioenergy using bark from a sawmill, what are the non-wooden products that could be substituted by paper?

According to the goal and scope in some LCA, it might not be advisable to calculate 'mixed' functional units by system expansion or substitution, e.g. establishment of public data bases. Therefore, allocation procedures are required, which are outlined in the following section.

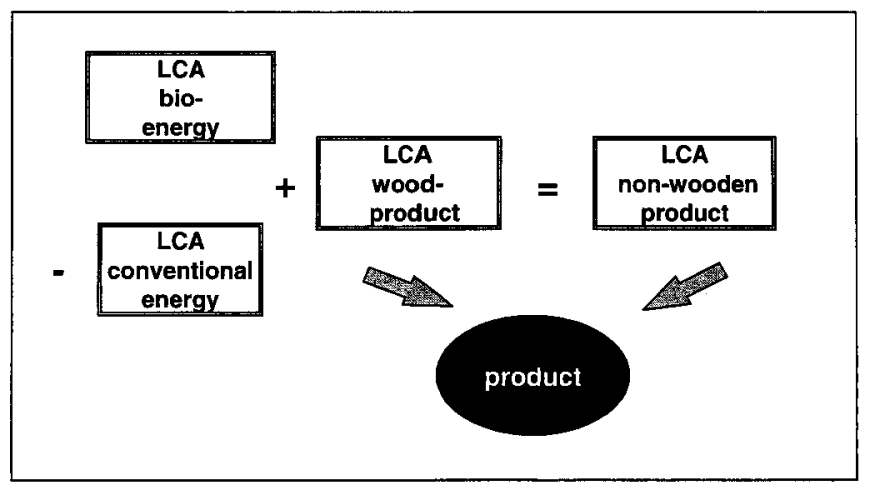

Fig. 4: Comparison of wood-based products with non-wooden products in an LCA by substitution of energy 


\subsection{Second priority procedure: allocation of unit processes}

The second priority to deal with the multi-functionality problem of LCA is to allocate unit processes to the various products. It is generally agreed that only products with a positive economic value, which are the 'aim of the process' or the 'intended output', shall carry environmental burdens related to the process (see e.g. ISO 14 041; Robson and Esser [9]). This agreement certainly has a subjective and case specific component depending on the goal and scope of the study. Even outcomes of low market price can be considered as co-products of the wood processing industries, if the structure of the acquiring industrial sector depends on these outflows and would otherwise have to be substituted by virgin material.

In LCA of wood-based products (see Fig. 2), the following allocation procedures are discussed: no allocation (all to the 'intended product'), mass/volume and market price (in fact, the relative share of proceeds). From the practical experience of the Cost E9 delegates, it is also possible to use different allocation factors within one LCA sawmill.

\section{References}

[1] Werner F, Richter K, Bosshart S, Frischknecht R (1997): Ökologischer Vergleich von Innenbauteilen am Bsp. von Zargen aus Massivholz, Holzwerkstoff und Stahl (Ecological comparison for indoor building materials - Comparison of frames made of solid wood, fibre wood and steel), EMPA/ ETH-Forschungsbericht, Dübendorf, Zürich

[2] Frischknecht R, Hofstetter P, Knoepfel I, Ménard M (1995): Relevanz der Infrastruktur in Ökobilanzen - Untersuchungen anhand der Ökoinventare für Energiesysteme (Relevance of infrastructure in life cycle assessments - Outlined with examples from LCA of energy systems). ETH Zürich, Zürich
[3] Ekvall T (2000): A Market-based Approach to Allocation at Open-loop Recycling. In: Resources, Conservation and Recycling, 29 (1-2): 91-109

[4] Plätzer E, Hamm U, Göttsching L (1996): Ökobilanzen: Lassen sich Umweltbelastungen gerecht auf die Papierkette verteilen? (Life cycle assessment: Is it possible to allocate environmental loads fairly on the paper chain?) In: Papier, $50(10 \mathrm{~A}): \mathrm{V} 63-\mathrm{V} 70$

[5] Reichart I, Hischier R, Schefer H, Zurkirch M (2001): Ökobilanz Medienkonsum - Elektronisch versus Print (Life cycle assessment of media consumption - electronic versus paper). EMPA-Forschungsbericht, St. Gallen

[6] Consoli F, Allen D, Boustead I, Fava J, Franklin W, Jensen AA, de Oude N, Parrish R, Perriman R, Postlethwaite D, Quay B, Seguin J, Vigon B (1993): Guidelines for Life-Cycle Assessment: a Code of Practice. 1st edition, Society of Environmental Toxicology and Chemistry (SETAC), Brussels, Washington, DC

[7] De Feyter S (1995): Handling of the Carbon Balance of Forests in LCA. In: Frühwald A, Solberg B (eds.): Life-Cycle Analysis A Challenge for Forestry and Forest Industry. EFI Proceedings No 8, European Forest Institute, Hamburg, 33-39

[8] Jungmeier G, Schwaiger H, Spitzer J (1998): The Treatment of Fossil Energy Substitution in LCA for Forest Products Criteria and Case Studies, published in proceedings of Cost E9 Workshop 'Life Cycle Assessment of Forestry and Forest Products', 14-16 September 1998

[9] Robson DJ, Esser P (1999): Life-Sys Wood: Consistent Life Cycle Analysis of Wood Products, Contract no. FAIR-CT950726, Consolidated Report. TNO, Helsinki

Received: May 9th, 2001 Accepted: August 5th, 2002 OnlineFirst: August 12th, 2002

\section{Part II of this paper}

to be published in Int J LCA 7 (6) 2002

will present examples from different case studies which are outlined to substantiate the reasoning from Part I.

The examples are taken from LCA studies in which the authors were involved. The examples are given in an order following that of the wood chain. In two examples - recycling of particle boards, combined heat and power production - an allocation is avoided; in the other examples, one or more different allocation procedures are applied:

Section 1.1:

Forestry

Section 1.2:

Sawmill

Section 1.3:

Windows

Section 1.4:

Bio-energy

Section 1.5:

Combined heat and electricity

Section 1.6:

Recycling 